\title{
PENGARUH UMUR BETINA Drosophilla melanogaster strain tx TERHADAP JUMLAH ANAKAN DAN JENIS KELAMIN F1 SEBAGAI BAHAN PANDUAN PRAKTIKUM GENETIKA
}

\author{
Antik Nur Wijayanti ${ }^{1}$, Marheny Lukitasari ${ }^{2}$, \\ ${ }^{1,2)}$ Program Studi Pendidikan Biologi, FPMIPA IKIP PGRI Madiun \\ e-mail: marh3ny@yahoo.com
}

\begin{abstract}
Every living organism has the ability to reproduce that aims to maintain the kind (species). Sexual maturity conditions of Drosophilla melanogaster will affect the outcome of the offspring, that is a number of offspring and a kind offspring sex. Sexual maturation of female D. melanogaster individuals also greatly affect to the offspring conditions. Genetic research using D. melanogaster as an experimental material will be interesting and challenging for the university students. The purpose of this study was to determine: 1)The effect of age of female D. melanogaster strains tx on offspring number and the sex of F1.2) The research results will use as a guide to the preparation of the genetics lab. The study was conducted using a completely randomized design methods. Data were analyzed using analysis of variance of the path (oneway Anova) followed further test by $5 \%$ BNT test. Data showed the effect of age of female D. melanogaster strains tx on a number of offspring and the kind sex of $F 1$. The average number of offspring at various ages females are 149.38. The average of are 72.03 and 77.34 of the female. After further testing with BNT in 5\% of level indicates that the number of F1 offspring in females treatment aged 12,24,36 and 48 hours resulted in a lot of different number of offspring significantly with the number of female progeny from crosses age 60,72, 84 and 96 hours resulted in the number of little offspring. From the study it can be concluded that the age of the female D. melanogaster strains tx effect on a number of offspring and a kind of F1 sex of progeny. The older females, the number of offsprings produced are less, because females decreased fertility and fecundity. Individual males have a higher mortality compared with all age female D. melanogaster strains tx.
\end{abstract}

Keyword: Females Age , D. melanogaster strain Tx, Practical Guidelines .

\section{PENDAHULUAN}

Setiap makhluk hidup memiliki kemampuan untuk melakukan reproduksi yang bertujuan untuk mempertahankan jenisnya (species). Kelestarian spesies secara keseluruhan mengharuskan tiap individu memperbanyak diri. Tiap generasi menghasilkan individu baru untuk menggantikan yang mati tanpa reproduksi suatu spesies akan punah. Lebih lanjut Campbell (2009) menyatakan bahwa Ilmu yang mempelajari tentang sifat-sifat yang diwariskan, proses penurunan sifat (hereditas), dan variasi yang terjadi pada keturunannya disebut ilmu genetika. Salah satu subyek penelitian yang dapat digunakan untuk mempelajari ilmu ini adalah lalat buah D. melanogaster.

Genetika sebagai salah satu cabang ilmu pengalaman (experienced sciences) merupakan ilmu yang yang sangat menarik dan sekaligus menantang. Hal ini disebabkan setiap makhluk hidup, khususnya makhluk hidup tingkat tinggi (multiseluler) melakukan perkawinan atau persilangan antar sesama jenisnya. Fenomena kawin terjadi secara alamiah dan sangat menarik untuk diamati tetapi kurang diimplementasikan dalam pembelajaran genetika bagi mahasiswa.

Berkenaan dengan umur betina $D$. Melanogaster, King (1970) dalam Muliati (2000) menyatakan bahwa jumlah telur yang yang diproduksi oleh individu betina D. melanogaster bervariasi tergantung umur betina, kelembaban dan nutrisi. Fowler (1973) dalam Muliati (2000) melaporkan individu betina $D$. melanogaster dapat mengelurkan ovum rata-rata 64 butir per hari, sehingga jika 
individu betina mampu hidup selama 30 hari, individu tersebut dapat menghasilkan 2000 telur.

Berkaitan dengan individu betina Cockburn, et al. (2002) dalam Long \& Pischeda (2005) mangemukakan bahwa kondisi betina juga mempengaruhi rasio seks F1. Betina dapat meningkatkan kemampuannya untuk menghasilkan keturunan dengan cara kawin dengan jantan "high-quality" untuk menghasilkan anakan jantan dan kawin dengan jantan "lowquality" untuk menghasilkan anakan betina.

Perkembangbiakan D. melanogaster dilakukan secara seksual dengan berbagai situasi dan kondisi yang dapat mempengaruhi keberhasilan kawinnya. Perkawinan pada D. melanogaster dimulai ketika hewan tersebut telah mencapai kedewasaan seksual. Menurut Indayati (1999) dalam Widya (2010) mengemukakan bahwa kedewasaan seksual pada individu jantan ditandai dengan kemampuan menghasilkan dan mengeluarkan sperma, sedangkan pada individu betina ditandai dengan kemampuan dalam mengovulasikan ootid.

Fowler (1973) dalam Hartanti (1998) menyatakan bahwa pada umumnya individu jantan akan kawin ketika sudah mencapai kematangan seksual yaitu kirakira berumur 12 jam setelah menetas. Pada individu betina mereka tidak akan kawin selama selang waktu 12 jam pertama setelah keluar dari pupa. Biasanya individu betina akan menolak kawin dengan jantan, hal tersebut menunjukkan bahwa individu betina belum mencapai aktivitas maksimum kematangan seksual sampai berumur 48 jam. D. melanogaster dianggap telah mencapai kedewasaan seksual setelah mampu menghasilkan dan mengeluarkan spermatozoa (untuk individu jantan) dan ootid (untuk individu betina).

$\begin{array}{crr}\text { Kondisi } & \text { kedewasaan } & \text { seksual } \\ \text { individu } & \text { D. melanogaster akan }\end{array}$ mempengaruhi hasil dan kondisi keturunannya, baik jumlah keturunan maupun jenis kelamin keturunan. Kematangan seksual individu betina $D$. melanogaster juga akan berpengaruh terhadap kondisi keturunannya. Oleh karena itu, penelitian ini penting dilakukan untuk mengetahui pengaruh umur betina $D$. melanogaster terhadap jumlah anakan dan jenis kelamin F1.

Penelitian ilmu genetika dengan menggunakan $D$. melanogaster sebagai bahan percobaan akan menarik dan menantang bagi mahasiswa. Selama ini mahasiswa hanya mendapatkan teori mengenai ilmu genetika namun belum berperan aktif dalam proses pembelajaran genetika secara praktis dan aplikatif. Pembelajaran genetika sekarang ini masih sangat tradisional sehingga perlu adanya peningkatan pembelajaran genetika yang berkembang seiring dengan perkembangan IPTEK dan bioteknologi.

Berdasarkan penjelasan di atas maka dilakukan penelitian ini yang bertujuan untuk mengetahui pengaruh umur betina $D$. melanogaster strain tx terhadap jumlah anakan dan jenis kelamin F1, serta penggunaan hasil penelitian sebagai bahan penyusunan panduan praktikum genetika.

\section{METODE}

Alat yang digunakan dalam penelitian antara lain botol selai, kain kasa, tutup botol dari spons, kertas label, timbangan, pengaduk, kantong plastik bening, gunting, panci, blender, kompor gas, pisau, kuas, selang, kertas pupasi dan spidol permanen. Bahan yang diperlukan dalam penelitian adalah Drosophila melanogaster strain tx, pisang rajamala, tape singkong, gula merah, air, yeast, deterjen.

\section{Peremajaan stok induk D. melanogaster strain tx}

Menyiapkan beberapa botol selai yang telah berisi medium lengkap dengan yeast dan kertas pupasi. Memulai peremajaan jika pada stok awal telah banyak ditemukan larva dengan cara memasukkan beberapa pasang $D$. melanogaster strain tx dari stok tersebut ke dalam botol baru dengan cara menggunakan sedotan yang terbuat dari selang plastik. 
Memberi identitas dengan kertas label pada medium berupa tanggal peremajaan pada botol selai yang telah berisi $D$. melanogaster strain tx tersebut. Menunggu hingga muncul pupa yang menghitam (pupa terbentuk setelah 6-7 hari setelah dikawinkan) kemudian mengisolasi pupa dalam selang ampul.

\section{Pengumpulan D. melanogaster strain tx} Menyiapkan selang plastik sepanjang $\pm 8 \mathrm{~cm}$. Memasukkan irisan pisang rajamala ditengah selang sampai membagi selang tersebut kurang lebih sama panjangnya. Memindahkan pupa yang menghitam dari stok induk ke selang ampul dengan menggunakan kuas pada kedua sisi selang. Menutup kedua sisi selang dengan menggunakan potongan spons. Menunggu pupa menetas sampai terbentuk individu baru untuk diperlakukan sesuai dengan tingkatan perlakuan yaitu umur betina yang diinginkan yaitu umur betina 12 jam, 24 jam, 36 jam, 48 jam, 60 jam, 72 jam, 84 jam dan 96 jam. Memberi label untuk menunjukkan individu baru tersebut menetas (tanggal dan jam).

\section{Persilangan D. melanogaster strain tx}

Menyiapkan botol yang telah berisi medium kultur sesuai dengan jumlah persilangan dan ulangannya. Menyilangkan pupa yang telah menetas sesama strain tx (ótx >< otx). Menyilangkan satu ekor jantan (umur 1-3 hari) setelah menetas dengan satu ekor betina umur 12 jam setelah menetas selama 5 jam dan memberi label botol "A". Masing-masing persilangan dilakukan sebanyak 4 kali ulangan. Setelah muncul larva, memindahkan individu betina dari botol "A"ke botol "B" dan mengamati jumlah imago yang menetas dari pupa pada botol "A" serta mengamati jenis kelamin F1 setiap hari sampai hari ke-7. Mengamati individu betina di botol "B", jika pada botol "B" telah ada larva, maka memindahkan induk betina ke dalam botol " C" dan seterusnya hingga individu betina mati. Mengamati jumlah anakan dan jenis kelamin F1 di botol "B" setiap hari selama 14 hari. Mengulangi prosedur yang sama untuk individu betina umur 24 jam, 36 jam, 48 jam, 60 jam, 72 jam, 84 jam dan 96 jam.

\section{HASIL DAN PEMBAHASAN}

\section{Jumlah anakan D. melanogaster Strain} Tx

Rata-rata jumlah anakan pada berbagai perlakuan umur betina maka disajikan dalam histogram seperti pada Gambar 1.

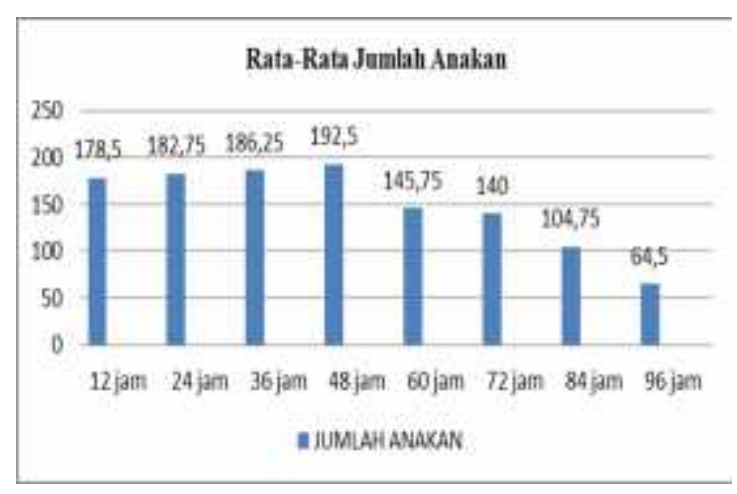

Gambar 1. Histogram rata-rata umlah anakan pada berbagai umur betina $D$. melanogaster Strain Tx

Rata-rata jumlah anakan D. melanogaster strain tx pada setiap perlakuan umur betina $12,24,36,48,60$, 72, 84, 96 jam adalah 149.38 dan umur betina 48 jam menunjukkan jumlah ratarata anakan paling banyak yaitu 192.5, sedangkan umur betina 96 jam menunjukkan jumlah rata-rata anakan paling sedikit yaitu 64,5.

Hasil analisa data menunjukkan bahwa pada umur betina $D$. melanogaster strain tx sangat berpengaruh terhadap jumlah anakan. Uji lebih lanjut BNT 5\%, menunjukkan umur betina 12, 24, 36 dan 48 jam jumlah anakan paling banyak dan ratarata paling besar yaitu 192,50 pada umur betina 48 jam. Sedangkan umur $60,72,84$ dan 96 jam mengalami penurunan jumlah anakan dan umur 96 jam rata-rata jumlah anakan paling sedikit yaitu 64,50, hal tersebut dikarenakan kondisi kedewasaan seksual individu betina $D$. melanogaster yang mempengaruhi hasil jumlah keturunannya. Hal ini sesuai dengan Frida (2002) yang menyatakan bahwa individu betina $D$. melanogaster umur 2 hari atau 48 
jam setelah menetas merupakan kondisi yang baik karena pada umur individu betina tersebut paling tinggi daya reseptivitasnya.

Fekunditas betina pada setiap perlakuan umur betina $D$. melanogaster adalah berbeda. Semakin tua umur betina maka semakin menurun fekunditas atau kesuburannya, sehingga semakin menurun tingkat fertilitas betina yang menyebabkan jumlah anakan menjadi semakin sedikit. Berkenaan dengan fekunditas umur betina D. melanogaster, Somashekar et al. (2011) melaporkan umur betina $D$. melanogaster muda 1-2 hari memiliki fekunditas yang tinggi dan paling subur dalam keberhasilan kawin (mating succes) yang dapat menghasilkan total telur 50 butir dibandingkan dengan umur betina dewasa dan umur betina tua. Lebih lanjut Sgro et al. (2000) menyatakan bahwa semakin tua umur betina maka semakin menurun fertilitasnya.

Hasil penelitian menunjukkan pada umur betina 48 jam dihasilkan jumlah anakan paling besar, ini berarti bahwa kedewasaan seksual D. melanogaster sebagian besar mengalami kematangan seksual pada umur 48 jam setelah menetas. Individu betina tidak akan kawin selama selang waktu 12 jam pertama setelah keluar dari pupa, dan biasanya menolak kawin dengan jantan. Hal tersebut dikarenakan individu betina belum mencapai aktivitas maksimum kematangan seksual sampai berumur 48 jam. Berkenaan dengan individu betina D. melanogaster King (1970) dalam Muliati (2000) menyatakan bahwa jumlah telur yang yang diproduksi oleh individu betina $D$. melanogaster bervariasi tergantung umur betina, kelembaban dan nutrisi. Fowler (1973) dalam Muliati (2000) melaporkan individu betina $D$. melanogaster dapat mengelurkan ovum rata-rata 64 butir per hari, sehingga jika individu betina mampu hidup selama 30 hari, individu tersebut dapat menghasilkan 2000 telur.

\section{Jenis Kelamin FI D. melanogaster Strain} $T x$
Berdasarkan deskriptif data jenis kelamin individu jantan dan betina F1 maka disajikan dalam histogram seperti pada Gambar 2.

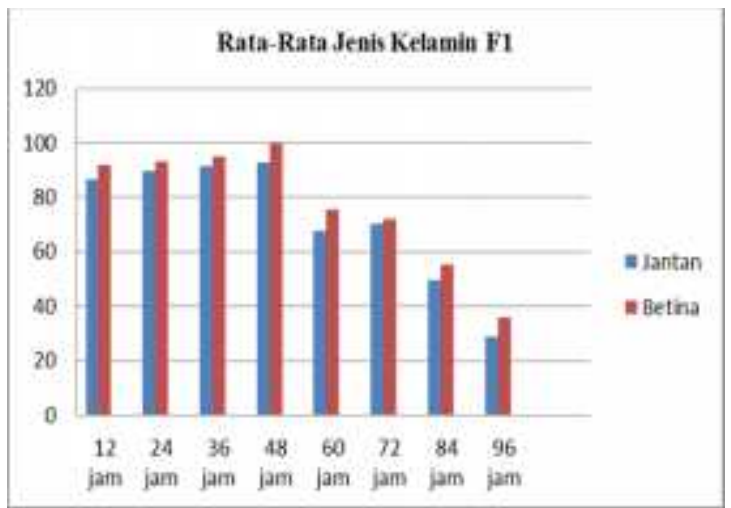

Gambar 2. Histogram rata-rata jenis kelamin $\mathrm{f} 1$ pada berbagai umur betina $D$. melanogaster strain $\mathrm{tx}$

Jenis kelamin individu jantan $D$. melanogaster strain tx pada berbagai umur betina diperoleh rata-rata sebesar 72,03 dan jenis kelamin individu betina $D$. melanogaster strain tx diperoleh rata-rata sebesar 77,34.

Hasil analisa data yang dilakukan menunjukkan ada pengaruh umur betina terhadap jenis kelamin anakan F1. Hal ini berarti kedewasaan seksual individu betina mempengaruhi jumlah jenis kelamin anakan jantan dan betina, sehingga dengan kematangan seksual individu betina maka jumlah anakan jantan dan betina semakin banyak yang dihasilkan. Dalam hal ini diasumsikan bahwa individu betina mencapai aktivitas maksimum kematangan seksual sampai umur 48 jam.

Uji lanjut BNT dengan taraf 5\%, menunjukkan umur betina 12, 24, 36 dan 48 jam menghasilkan jumlah individu jantan dan individu betina paling banyak dibanding umur betina 60, 72, 84 dan 96 jam . Sebagaimana hasil penelitian tentang jumlah individu jantan dan betina yang telah dikemukakan, hal tersebut diduga terkait dengan kemampuan reproduksi individu betina pada umur muda $(12,24,36$ dan 48 jam) yang mencapai aktivitas maksimum kematangan seksual individu betina sehingga jumlah anakan jantan dan 
betina yang dihasilkan paling banyak. Hasil penelitian tentang jenis kelamin anakan F1 memperlihatkan adanya individu jantan dan individu betina. Hal ini sesuai dengan pernyataan Corebima (2003) yang menyatakan bahwa dari hasil gametogenesis pada hewan-hewan multiseluler, termasuk manusia, memang menghasilkan gamet (jantan dan betina) dengan demikian jenis kelamin yang menghasilkan gamet jantan dan betina dipengaruhi oleh faktor genetik.

Penelitian ini menunjukkan hasil yang berbeda pada jumlah anakan individu jantan dan individu betina yang dihasilkan pada setiap perlakuan umur betina. Jumlah anakan individu jantan dan individu betina umur muda yaitu umur 12, 24, 36 dan 48 jam menunjukkan hasil yang paling besar dibandingkan dengan umur tua 60, 72, 84 dan 96 jam. Hal ini berarti pada betina umur 48 jam tampak menghasilkan anakan jantan lebih banyak dibanding betina umur 12 jam. Dengan demikian rasio anakan individu jantan paling banyak di usia kawin umur betina 48 jam. Hal ini sesuai dengan pernyataan Cockburn, et al (2002) dalam Long and Pischeda (2005) yang manyatakan bahwa kondisi betina juga mempengaruhi rasio seks F1. Betina dapat meningkatkan kemampuannya untuk menghasilkan keturunan dengan cara kawin dengan jantan "high-quality" untuk menghasilkan anakan jantan dan kawin dengan jantan "low-quality" untuk menghasilkan anakan betina. Hal ini menunjukkan bahwa F1 D. melanogaster dipengaruhi oleh beberapa faktor yang berhubungan dengan lingkungan maupun internal induk jantan dan betina.

Hasil analisis secara keseluruhan jumlah rerata jenis kelamin individu jantan dan betina menunjukkan bahwa rerata individu jantan F1 adalah 72,03 sedangkan rerata untuk individu betina adalah 77,34. Hal ini berarti bahwa jumlah anakan individu betina lebih banyak dibandingkan dengan jumlah anakan individu jantan pada persilangan D. melanogaster strain tx. Hasil penelitian dapat dijelaskan bahwa diduga berkaitan dengan viabilitas atau kemampuan untuk hidup yang tidak sama antara individu jantan dan individu betina pada semua perlakuan umur betina sehingga jumlah rerata individu jantan lebih rendah bila dibanding individu betina. Hal ini sesuai yang dilaporkan Maxson (1985) dalam Muliati (2000) yang menyatakan bahwa individu jantan beberapa spesies mempunyai jumlah kematian yang lebih tinggi dibanding dengan yang betina pada semua umur. Dalam hal ini jika terjadi kematian pada individu jantan pada tahap larva, pupa maupun imago memungkinkan jumlah turunan betina menjadi lebih besar.

Hasil analisa data tentang jenis kelamin hasil persilangan $D$. melanogaster strain tx yang menunjukkan bahwa jumlah anakan $D$. melanogastetr betina lebih besar daripada jumlah anakan jantan. Hal tersebut dikarenakan pada saat proses kawin individu jantan D. melanogaster memproduksi lebih banyak gamet yang membawa kromosom $\mathrm{X}$, dalam hubungan ini jika terjadi fertilisasi maka memungkinkan jumlah keturunan individu betina menjadi lebih besar dibandingkan individu jantan. Hasil penelitian menunjukkan bahwa penjelaskan tersebut tidak sejalan dengan pernyataan Corebima (2003) yang menyatakan bahwa perkawinan D. melanogaster jantan dan betina akan menghasilkan keturunan F1 yang berjenis kelamin jantan (XY) dan betina $(\mathrm{XX})$ dengan perbandingan masingmasing 50\%. Berkenaan dengan jumlah jenis kelamin dari hasil penelitian Rothwell (1983) dalam Farida (1996) menyatakan bahwa untuk individu dengan tipe penentuan jenis kelamin XY seperti pada $D$. melanogaster ini, individu jantan dan betina akan memproduksi gamet dengan jumlah yang kurang lebih sama akibatnya kromosom $\mathrm{X}$ dan $\mathrm{Y}$ memiliki jumlah yang sama, sebagai hasilnya akan diperoleh keturunan jantan dan betina dengan nisbah $1: 1$.

Implementasi Hasil Penelitian sebagai Bahan Penyusunan Petunjuk Praktikum 
Praktikum genetika dengan menggunakan D. melanogaster sebagai bahan percobaan akan menarik dan menantang bagi mahasiswa. Untuk memudahkanmahasiswa dalam melakukan praktikum, perlu adanya penyusunan petunjuk praktikum sehingga mahasiswa dapat melakukan praktikum sesuai dengan prosedur yang ada. Pembelajaran SainsBiologi khususnya genetika menekankan pada sebuah pembangunan konsep-konsep dasar pengetahuan untuk dikaitkan pada sebuah refleksi natural (alamiah) dalam pembelajarannya.

Buku petunjuk praktikum genetika perlu diberikan pada jenjang pendidikan di Perguruan Tinggi dan hasil penelitian ini dapat dipergunakan sebagai bahan panduan praktikum genetika di Perguruan Tinggi. Hal ini dikarenakan prosedur penelitian tidak terlalu rumit sehingga mahasiswa tidak mengalami kesulitan dalam melakukan penelitian, bahan dan alat yang digunakan mudah untuk didapat, parameter yang diamati juga sederhana yaitu berhubungan dengan bentuk morfologi $D$. melanogaster serta jumlah anakan hasil persilangan sesama strain. Hasil analisis yang demikian ini ternyata sesuai dengan pernyataan Seregeg (1996) bahwa $D$. melanogaster merupakan salah satu organisme terbaik untuk percobaan hereditas, sebab mudah sekali dipelihara di laboratorium, makanannya sangat sederhana dan ruang yang dibutuhkan sangat kecil, siklushidupnya pendek, 7-8 hari (untuk Indonesia), keturunannya banyak dan memilki banyak variasi yang herediter. Lebih lanjut Nio et al. (1995) yang menyatakan bahwa $D$. melanogaster memiliki ukuran tubuh cukup besar untuk pengamatan dengan mata telanjang dan jumlah kromosomnya sedikit.

Hasil penelitian ini dapat digunakan untuk memberikan gambaran langsung pada mahasiswa agar tidak hanya mempunyai gambaran teoritis saja tetapi dengan melakukan praktikum genetika secara langsung sehingga mahasiswa mampu menanamkan konsep dasar genetika dengan lebih mendalam serta melatih dan memberikan motivasi kepada mahasiswa untuk bekerja keras dan mengutamakan kejujuran dalam menghasilkan data serta menjalani proses perkuliahan secara keseluruhan.

\section{SIMPULAN}

Ada pengaruh umur betina $D$. melanogaster strain tx terhadap jumlah anakannya.Umur betina $D$. melanogaster strain tx 48 jam merupakan umur yang paling banyak menghasilkan jumlah anakan dan memiliki daya reseptifitas dan fekunditas paling tinggi, sedangkan umur betina $D$. melanogaster strain tx 96 jam menghasilkan jumlah anakan paling sedikit. Umur betina $D$. melanogaster strain tx memperlihatkan adanya pengaruh terhadap rasio seks atau jenis kelamin anakan $\mathrm{F} 1$. Penelitian tentang pengaruh umur betina $D$. melanogaster strain tx dapat dijadikan sebagai bahan panduan praktikum genetika.

\section{DAFTAR PUSTAKA}

Campbell, Neil A. 2009. Biology Concepts \& Connections Sixth Edition. St.San Francisco:Pearson

Corebima A.D. 2003.Genetika Mendel. Surabaya: Airlangga University Press

Farida, 1996. Pengaruh Suhu Terhadap Nisbah Kelamin D. melanogaster. Disertasi tidak diterbitkan. Malang: Universitas Negeri Malang.

Farida M.Y, 2002. Pengaruh Macam Strain dan Umur Betina, serta Macam Strain Jantan Terhadap Reseptivitas Individu Betina D. melanogaster, untuk Melakukan Perkawinan Kembali. Jurnal MIPA Edisi Juli. Universitas Negeri Malang.

Hartanti S. 1998. Studi Kecepatan Kawin, Lama Kopulasi dan Jumlah Turunan D. melanogaster Strain black dan sepia pada Umur 2 dan 3 Hari. Disertasi. Malang: Universitas Negeri Malang. 
Long T.A.F. \& Pischedda A. 2005. Do female $D$. melanogaster adaptively bias offspring sex ratios in relation to the age of their mate. Proc. R. Soc., 272 : 1781-1787.

Muliati L. 2000. Pengaruh Strain dan Umur Jantan terhadap Jumlah Turunan jantan dan Betina. Disertasi. Malang: Universitas Negeri Malang.

Nio T.K. 1995. Diktat Genetika Dasar. Bandung : ITB.

Seregeg W.,1996. Penuntun Praktikum Genetika. Surabaya: IKIP Surabaya.

Sgro CM, Patridge L., Fowler K. \& Gissele Gedere. 2000. Selection age on Reproduction in D. melanogaster:
Female Mating as Frequency as Correlated Response. Evolution, 54 (6):2152-2155

Shoma S.K., Khrisna M.S, Hedge S.N, Jayaramu SC, 2011. Effect of Age on Female Reproductive Success in $D$. bipectinata. Journal of Insect Sciene. 11(3-4)

Widya D.K. 2010. Pengaruh Jeda Waktu Kawin Kembali (6, 12, 18, 24, 30 dan 36 jam) dan Macam Strain terhadap Keberhasilan Kawin Kembali Individu Betina Drosophila melanogaster strain ro, b, dan dp. Disertasi. Malang: Universitas Negeri Malang. 